\title{
PROBLEMS OF DIFFERENTIATION OF FLARES WITH RESPECT TO GEOPHYSICAL EFFECTS
}

\author{
HELEN W. DODSON and E. RUTH HEDEMAN \\ McMath-Hulbert Observatory of The University of Michigan, Michigan, U.S.A.
}

\section{INTRODUCTION}

In spite of much effort in recent years, the problems relating to the differentiation of flares with respect to terrestrial effects remain numerous. They stem not only from difficulties in securing and understanding flare observations but also from similar uncertainties with respect to the increasingly complex geophysical data. Many of the problems fall into four general categories:

1. Difficulty of securing complete and homogeneous $\mathrm{H} \alpha$ observations and data relating to solar flares.

2. Difficulty of obtaining and organizing the worldwide ionospheric and geomagnetic data in forms most suitable for appraisal of terrestrial effects of flares.

3. Ambiguity in identification of specific flares associated with specific terrestrial effects.

4. Inability, at the present time, to recognize critical differences between the flares that apparently are associated with certain terrestrial effects and those that are not.

It is generally accepted that certain solar flares are indeed the apparent sources of enhanced radiations and/or particle ejections that give rise to measurable changes in the geomagnetic field, the ionosphere, and the particle fields surrounding the Earth. However, according to world-wide statistics, flares with clearly associated geophysical effects constitute a relatively small fraction of all observed $\mathrm{H} \alpha$ flares. Two questions immediately arise: Do the flares with detectable geophysical effects differ from flares without such effects primarily by larger size, greater brightness, and perhaps more "favorable" position on the disk? Or is the difference more a matter of kind than degree? Do the flares with terrestrial effects differ in some fundamental way from flares without such effects? These are some of the questions that the solar observer constantly asks as he stands humble before the complexity of solar and geophysical data and tries to differentiate between flares on the basis of their known terrestrial consequences.

\section{PROBLEMS RELATING TO H $\alpha$ FLARE DATA}

\subsection{Inherent Uncertainties in All Tabulations of Flare Data}

The effort over decades by M. and Mme. d'Azambuja and other solar astronomers to secure a continuous watch of the solar disk in $\mathrm{H} \alpha$ radiation was brought to practical accomplishment through the organization of the $\mathrm{H} \alpha$ flare patrol for the International Geophysical Year. The solar disk was observed in $\mathrm{H} \alpha$ at least once in every five-minute interval for 95 per cent of the entire 18 months, July 1957-December 1958. Therefore, from the point of view of securing basic observations of flares, insofar as these can be recorded on small scale, center-of-H $\alpha$ photographs of the solar disk, very great progress has been made in recent years.

Many of the difficulties and imperfections in currently available $\mathrm{H} \alpha$ flare data result not from lack of observations but from the very nearly impossible task of preparing brief, 
meaningful reports of the exceedingly complex flare phenomena recorded on the films. Information about flares as simple as the times of start, maximum and end are really matters of judgment and points of view even when abundant photographic and photometric information is available. Reported intensities for flares are subject to profound uncertainties, and the reported area of a given flare reflects the adjustment of filter and telescope and the contrast of the photographic emulsion as well as the reporter's interpretation of the record. Finally, importance, which is currently based primarily on area, reflects all of these uncertainties. Solar flare observers are thoroughly aware of the problems and are trying to improve and standardize their reporting methods, but progress is slow. All too often, investigators from other disciplines fail to realize that lists of flares and subflares represent less than exact information.

Prior to the IGY, those who used flare data usually secured it from lists of reports of flares by individual observers in the Quarterly Bulletin of Solar Activity, and the uncertainty in the data was immediately apparent. The McMath-Hulbert Observatory Working List of Flares ${ }^{(1)}$ for the IGY and subsequent years, though providing a useful list of flare events, may inadvertently have done the investigator the disservice of masking the inherent uncertainties in flare data. Starting in January, 1963, the format of the portions of the Quarterly Bulletin of Solar Activity which report flare data will be changed and will contain only lists of flare events as in the Working Lists. The individual reports of flares will be made available through the F Series Bulletins of NBS-CRPL and World Data Centers. It should be noted that neither the McMath-Hulbert Observatory Working Lists of Flares nor the Quarterly Bulletins provide any information about the thousands of flares unambiguously reported as of importance $1-$. Data regarding these subflares should be sought from World Data Centers, the F-Series publications of NBS-CRPL, or examination of original solar records.

\subsection{Systematic Effects in Flare Data}

In addition to the inherent uncertainties in all tabulated data relating to solar flares, there are two systematic effects in the reports of flares that make the appraisal of the terrestrial consequences of flares especially difficult. The first stems from an apparent diminution in the visibility of $\mathrm{H} \alpha$ flares from center to limb. The reported number of flares in all importance categories diminishes with increasing central meridian distance. This has been characteristic of flare data since its first tabulation almost thirty years ago, and it is still present in the flare records for the IGY and subsequent ycars (Table 1 and Fig. 1a). In an effort to evaluate the probable area of the actual flare that occurred on the Sun, it has been recommended for many years that the apparent area of a flare be corrected for projection effects through multiplication by the secant of the angular distance of the flare from the center of the solar disk. Strict application of this correction process yields exceedingly large areas for features near the solar limb and might have been expected to result in systematic overestimation of importance for flares far from the center of the disk. This may have happened for certain individual flares, but it is not apparent as a systematic effect in the total flare data.

Severe ionospheric disturbances and even high-energy particle events have occurred in association with flares near the limb which have been reported as of only modest $\mathrm{H} \alpha$ importance $(1-$ to $1+)$. These observations should not be interpreted as meaning that the terrestrial effects accompanied a necessarily modest solar phenomenon. They do indicate that the $\mathrm{H} \alpha$ aspect of the complex flare event, as seen from the Earth, was not 
Table 1. Disk Distribution of Flares

\begin{tabular}{|c|c|c|c|c|}
\hline & \multicolumn{2}{|c|}{$\begin{array}{c}\text { IGY } \\
\text { (July 1957-Dec. 1958) }\end{array}$} & \multirow{2}{*}{ Imp. 3 and $3+$} & \multirow{2}{*}{$\begin{array}{c}\text { Flares } \\
\text { associated with } \\
\text { SWF's of imp. 3+ }\end{array}$} \\
\hline & Imp. $>1$ & Imp. $>2$ & & \\
\hline t $90^{\circ}$ & 147 & - & - & $8 \dagger$ \\
\hline $80-89^{\circ}$ & 222 & 12 & 3 & 7 \\
\hline $70-79^{\circ}$ & 240 & 17 & $7^{*}$ & 10 \\
\hline $60-69^{\circ}$ & 320 & 22 & 4 & 9 \\
\hline $50-59^{\circ}$ & 393 & 22 & 4 & 4 \\
\hline $40-49^{\circ}$ & 355 & 33 & 8 & 9 \\
\hline $30-39^{\circ}$ & 402 & 27 & 8 & 6 \\
\hline $20-29^{\circ}$ & 442 & 39 & 6 & 9 \\
\hline $10-19^{\circ}$ & 446 & 41 & 7 & 12 \\
\hline $00-09^{\circ}$ & 403 & 35 & 10 & 18 \\
\hline $\mathrm{W} 00-09^{\circ}$ & 424 & 32 & 8 & 12 \\
\hline $10-19^{\circ}$ & 464 & 35 & 6 & 6 \\
\hline $20-29^{\circ}$ & 464 & 30 & 5 & 16 \\
\hline $30-39^{\circ}$ & 452 & 36 & 10 & 13 \\
\hline $40-49^{\circ}$ & 391 & 32 & 4 & 9 \\
\hline $50-59^{\circ}$ & 368 & 34 & 6 & 10 \\
\hline $60-69^{\circ}$ & 281 & 29 & 5 & 14 \\
\hline $70-79^{\circ}$ & 251 & 13 & 2 & 9 \\
\hline $80-89^{\circ}$ & 184 & 14 & - & 8 \\
\hline W $90^{\circ}$ & 110 & 4 & 2 & $11 \dagger$ \\
\hline Total & 6759 & 507 & 105 & $200_{+}^{+}$ \\
\hline
\end{tabular}

* Excludes two in original data that were errors in transmission of data.

$\dagger$ Includes three cases at east limb and five at west limb of bright surges and loop-type prominences without flare on adjacent disk.

$\ddagger$ There were four additional SWF's of imp. $3 \pm$ for which we could find no observations or reports of concomitant solar activity.

\section{Disk Distribution of Flares}
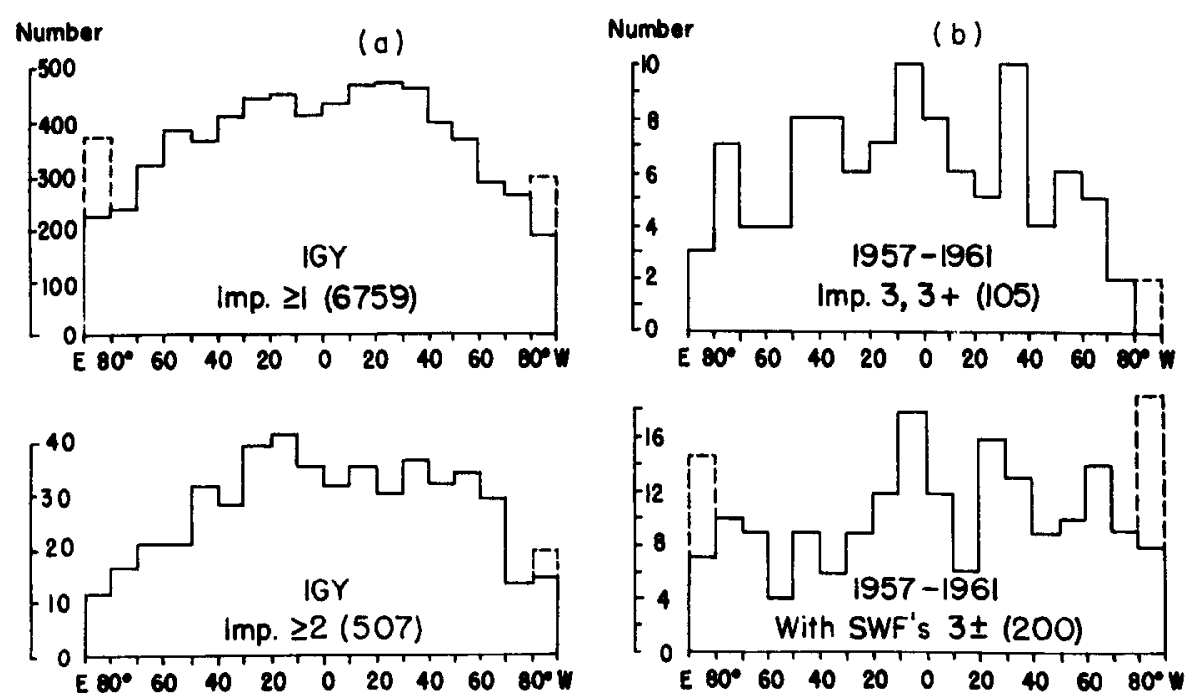

Fig. 1. DISK DISTRIBUTION OF FLARES FOR SPECIAL TIME INTERVALS, By IMPORTANCE AND BY ASSOCIATION WITH SHORT WAVE FADES. DOTTED LINES ENCLOSE DATA REFERRING TO CENTRAL MERIDIAN DISTANCE OF $90^{\circ}$. 
great, and that it is very difficult to deduce, from $\mathrm{H} \alpha$ records, the kinds of events that may be happening in a center of activity when it is near the edge of the apparent solar disk.

The second systematic effect in current $\mathrm{H} \alpha$ observations and reports of flares is not a consequence of solar circumstances but is man-made and reflects the great difficulty, in spite of best efforts and cooperation, to secure homogeneous, world-wide flare data. A summarizing tabulation ${ }^{(2)}$ of the flare data for the IGY showed that approximately twice as many flares of importance $>1$ were reported per hour from $05^{\mathrm{h}}$ to $16^{\mathrm{h}}$ U.T. as during the remainder of the Universal Day. Apparently certain of the observers for $05^{\mathrm{h}}$ to $16^{\mathrm{h}}$ U.T. reported as flares of importance $>1$ a large number of events that observers during the other hours of the day would have classified as subflares (area smaller than 100 millionths of solar hemisphere). This inhomogeneity continues to exist in flare data through 1962 and constitutes one of the major current problems of flare reporting (Table 2 and Figs. 2(a) and 2(b)).

\subsection{Efforts to Remove Systematic Effects in IG Y H $\alpha$ Flare Data}

Dr. Constance Warwick of the U.S. National Bureau of Standards, recognizing that these two systematic effects "present grave difficulties to the interpretation of the astronomical and geophysical statistics involving solar flares", has tried to remove them from the flare data for the IGY. In the faith that "differences that are understood can be removed"

TABLE 2. Distribution BY U.T. OF STARTS OF FLARES* AND SHORT-WAVE FadeS

\begin{tabular}{|c|c|c|c|c|c|}
\hline \multirow[b]{2}{*}{ U.T. } & (July 1957 & $1958)$ & & 961 & \multirow{2}{*}{$\begin{array}{c}\text { SWF's } \\
\text { July 1957-1962 } \\
\text { All SWF's } \\
\text { CRPL lists }\end{array}$} \\
\hline & Imp. $>1$ & Imp. $>2$ & Imp. $>1$ & Imp. $>2$ & \\
\hline $0^{\mathrm{n}}$ & 209 & 24 & 213 & 18 & 75 \\
\hline 1 & 171 & 13 & 167 & 14 & 58 \\
\hline 2 & 175 & 25 & 155 & 24 & 86 \\
\hline 3 & 170 & 19 & 183 & 16 & 75 \\
\hline 4 & 194 & 16 & 173 & 10 & 83 \\
\hline 5 & 286 & 21 & 238 & 17 & 81 \\
\hline 6 & 327 & 29 & 367 & 21 & 73 \\
\hline 7 & 456 & 42 & 536 & 36 & 89 \\
\hline 8 & 514 & 28 & 550 & 24 & 82 \\
\hline 9 & 512 & 36 & 476 & 22 & 79 \\
\hline 10 & 480 & 32 & 440 & 29 & 79 \\
\hline 11 & 400 & 29 & 384 & 22 & 66 \\
\hline 12 & 383 & 27 & 407 & 21 & 76 \\
\hline 13 & 447 & 23 & 386 & 24 & 103 \\
\hline 14 & 367 & 23 & 409 & 27 & 112 \\
\hline 15 & 319 & 9 & 333 & 23 & 110 \\
\hline 16 & 271 & 17 & 228 & 12 & 123 \\
\hline 17 & 177 & 11 & 161 & 16 & 125 \\
\hline 18 & 161 & 13 & 137 & 15 & 113 \\
\hline 19 & 166 & 15 & 156 & 7 & 93 \\
\hline 20 & 134 & 15 & 135 & 21 & 77 \\
\hline 21 & 142 & 17 & 154 & 16 & 51 \\
\hline 22 & 131 & 11 & 153 & 11 & 39 \\
\hline 23 & 170 & 12 & 143 & 8 & 48 \\
\hline Total & 6762 & 507 & 6684 & 454 & 1996 \\
\hline
\end{tabular}

* The flare counts are based on data in the McMath-Hulbert Observatory Working Lists of Flares. 

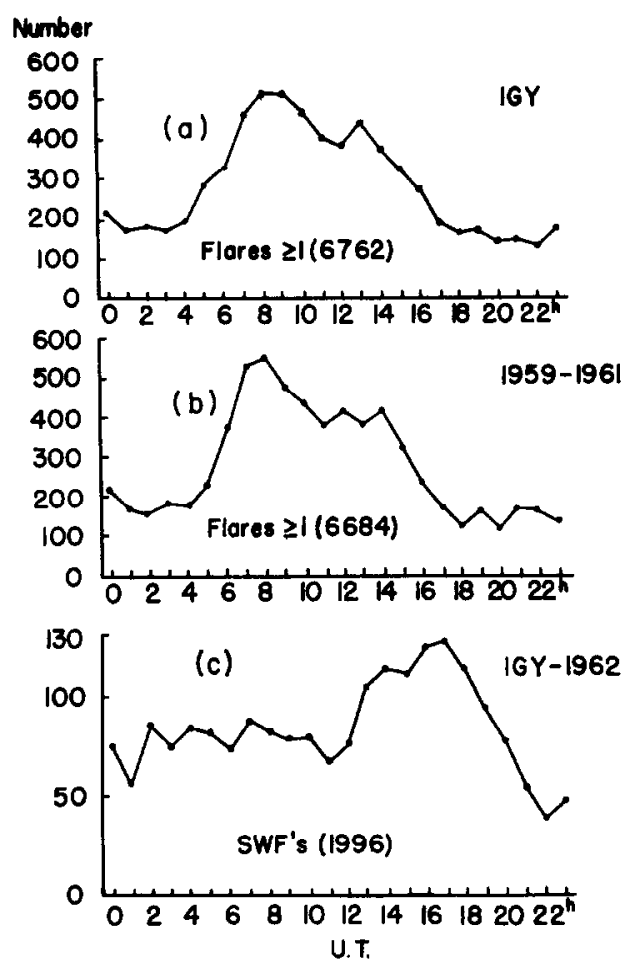

Fig. 2. Distribution IN UNIVERSAL TIME OF BEGINNINGS OF REPORTED FLARES AND SHORT WAVE FADES.

she has tried through extensive machine analysis of all available flare data for the IGY to determine the systematic errors present in the data and to remove them. The "National Bureau of Standards List of IGY Flares with Normalized Values of Importance and Area"(3) is the result of this program. This extensive list of flares and subflares for the IGY may make it possible to handle certain statistical aspects of the geophysical effects of flares with greater success than could have been achieved with closer adherence to the original reports.

\section{Ha FLARES AND IONOSPHERIC DISTURBANCES}

\subsection{Problems of Obtaining and Organizing World-Wide Ionospheric Data for Comparison with Solar Flares}

Information and data relating to variations in the ionosphere are vast. The solar astronomer usually must depend upon carefully prepared lists of ionospheric disturbances for information relating to the occurrence or absence of ionizing radiation with specific flares. Flare-associated ionospheric disturbances generally occur only in the sunlit hemisphere and their severity at any one station depends upon the position of the subsolar point as well as upon the intensity of the original ionizing radiation. In recent years, as more stations have contributed to the world-wide ionospheric patrol, the published lists of ionospheric disturbances have grown in length and have provided more nearly complete coverage of these flare-associated phenomena. The authors are most familiar with the reports of world-wide ionospheric disturbances prepared by the Central Radio Propagation 


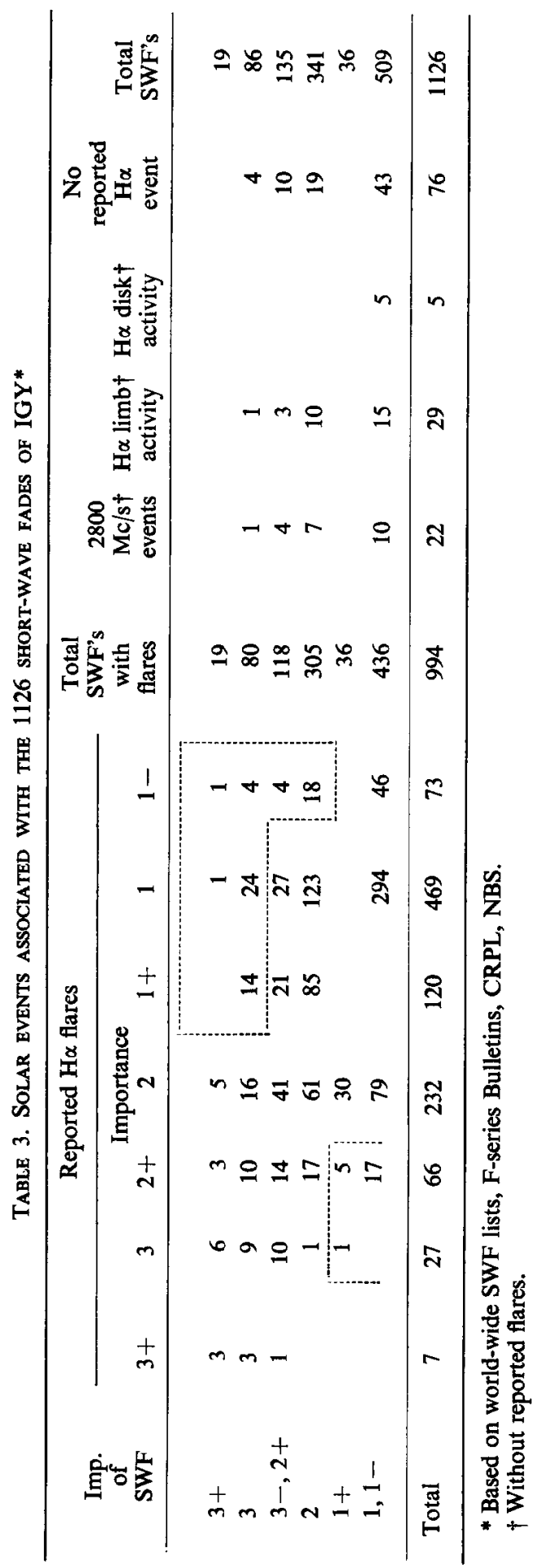


Laboratory of the U.S. National Bureau of Standards under the supervision of Miss Virginia Lincoln. It is our understanding that these reports from NBS are as nearly complete as current information in World Data Centers can make them.

An estimate of the completeness and homogeneity of the CRPL lists of SWF's can be made from the plot of the number of SWF's vs. the Universal Time of their beginning for

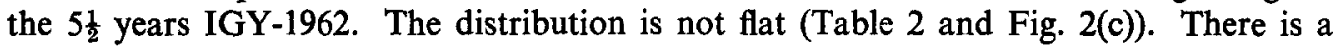
conspicuous maximum from $13^{\mathrm{h}}$ to $19^{\mathrm{h}}$ U.T. and a deep minimum, $21^{\mathrm{h}}-23^{\mathrm{h}}$. These systematic effects in the world-wide SWF data make the evaluation of ionizing radiation from flares especially difficult. Furthermore, since a high proportion of the SWF's from $13^{\mathrm{h}}$ to $19^{\mathrm{h}}$ are well confirmed and show excellent time association with flares, it is probable that large numbers of flare-associated ionospheric disturbances for the remainder of the Universal Day have missed detection.

\subsection{Flares and Short-Wave Fades During the IGY}

The CRPL lists of confirmed short-wave fades for the IGY show 1126 entries. These have been compared with published lists of flares, subflares, and other forms of solar activity. The results are summarized in Table 3 . The comparison indicates that 994 , or 88 per cent of the 1126 reported SWF's, occurred in suitable time association with flares and subflares. Of the 994 SWF's so associated, 91 per cent agree in importance of flare and SWF within our estimate of the probable uncertainties of the assignment of importance (i.e. \pm 1 importance class). There are cases of apparent serious imbalance between the magnitude of the SWF and the associated flare and these cases are surrounded by dotted lines in Table 3.

Table 4. Distribution of flares during IGY By importance and OCCURRence OF CONFIRMED SHORT-WAVE FADES

\begin{tabular}{|c|c|c|c|}
\hline \multirow[b]{2}{*}{ Importance } & \multirow[b]{2}{*}{ Number } & \multicolumn{2}{|c|}{$\begin{array}{l}\text { Confirmed associated } \\
\text { short-wave fades } \dagger\end{array}$} \\
\hline & & Number & Per cent \\
\hline $\begin{array}{l}3 \text { and } 3+ \\
2 \text { and } 2+ \\
1 \text { and } 1+5315\end{array}$ & $\begin{array}{r}39 \\
467\end{array}$ & $\begin{array}{r}34 \\
298\end{array}$ & $\begin{array}{l}87 \\
64\end{array}$ \\
\hline $\left.\begin{array}{ll}(1-) & 835\end{array}\right\}$ & 6150 & 589 & 10 \\
\hline Total flares $(>1)$ & $6656 \neq$ & 921 & 14 \\
\hline $\begin{array}{l}\text { Estimate of number of } \\
\text { flares unambiguously } \\
\text { reported as 1- }\end{array}$ & $\sim 7000$ & 73 & $\sim 1$ \\
\hline
\end{tabular}

\footnotetext{
* From McMath-Hulbert Working List of IGY Flares.

$\dagger$ CRPL lists

$¥$ Approximately 100 flares with double maxima have been considered as single events in this tabulation but as two events in Table 2 .
}

For the IGY, the McMath-Hulbert Observatory Working List contains $6656^{*}$ entries of flares with importance $\Sigma 1$. Simple comparison of flare and SWF data shows concomitant ionospheric disturbances with 66 per cent of the flares of importance $>2$ and 10 per cent of the flares of importance 1 (Table 4). A study by Acton ${ }^{(4)}$ of the same flare and ionospheric data for 1958, similarly indicates concomitant SWF's for approximately 10 per cent of the flares of importance $>1$. In the $4 \frac{1}{2}$ years IGY-1961 more

* In this total, a double-maximum-flare is counted as a single event. 
than $13,000 \mathrm{H} \alpha$ flares of importance $>1$ were reported to World Data Centers, but in the same years only 1944 shortwave fades were listed by CRPL.

It may be true, as the world-wide data suggest, that only 10 to 15 per cent of the $\mathrm{H} \alpha$ fiares of importance $\bar{\Sigma} 1$ are accompanied by ionizing radiation, but this is contrary to the impression that we have gained over the years at the McMath-Hulbert Observatory as we have watched the occurrence of flares on the solar disk and concomitant changes in the 5 Mc WWV signal transmitted from Fort Belvoir, Va., U.S.A. Accordingly, we have made a special study of flares and ionospheric disturbances observed at the McMath-Hulbert Observatory since the start of the $\mathrm{H} \alpha$ flare patrol in 1958. We show, in Table 5, data for the 373

TABle 5. COMPARISON OF FLARES AND ASSOCIATED IONOSPHERIC DISTURBANCES (SWF's) MCMATH-HulbERT OBSERVATORY RECORDS, 1500-1859 UT February 1958-December 1961

\begin{tabular}{|c|c|c|c|c|c|c|}
\hline \multirow{2}{*}{$\begin{array}{c}\text { Flare } \\
\text { importance }\end{array}$} & \multirow{2}{*}{$\begin{array}{c}\text { Number } \\
\text { of } \\
\text { flares }\end{array}$} & \multicolumn{2}{|c|}{$\begin{array}{c}\text { SWF's } \\
\text { in CRPL lists }\end{array}$} & \multicolumn{2}{|c|}{$\begin{array}{c}\text { SWF's } \\
\text { on McM-H records }\end{array}$} & \multirow{2}{*}{$\begin{array}{l}\text { Percent of flares } \\
\text { with enhancements } \\
\text { of atmospherics } \\
\text { Ellison }^{(5)}\end{array}$} \\
\hline & & Number & Per cent & Number & Per cent & \\
\hline 3 & 8 & 8 & 100 & 8 & 100 & 100 \\
\hline 2 & 38 & 34 & 89 & 35 & 92 & 88 \\
\hline 1 & $327^{*}$ & 91 & 28 & 130 & 40 & 51 \\
\hline Total Imp. $>1$ & 373 & 133 & 36 & 173 & 46 & $\begin{array}{l}\text { (Based on study } \\
\text { of } 413 \text { flares.) }\end{array}$ \\
\hline
\end{tabular}

* Includes five flares originally classified as imp. 2, but called 1 or $1+$ in Working List. Excludes thirty-two flares that occurred at times when ionospheric record was so disturbed that it was not usable.

flares of importance $>1$ observed at the McMath-Hulbert Observatory from February 1958 to December 1961 at times when the ionospheric record was satisfactory, and for the four-hour interval $15^{\mathrm{h}}-19^{\mathrm{h}}$ U.T., the hours in which our WWV recorder is most efficient. According to this sample of flare and SWF data, all flares of importance 3, 89 per cent of the flares of importance 2, and 28 per cent of the flares of importance 1 were accompanied by ionospheric disturbances in the lists of CRPL. Furthermore, during the same intervals there were fades on our WWV records in good time association with 40 additional flares. The latter events did not receive world-wide confirmation, but coupled with the confirmed data they suggest that as many as 46 per cent of the flares of importance 51 may have emitted sufficient ionizing radiation to have caused ionospheric disturbances detectable on this type of equipment. These percentages are much higher than those indicated by the total IGY data, but they are in essential agreement with those found by Ellison ${ }^{(5)}$ in 1953 in a study of sudden enhancements of atmospherics associated with $413 \mathrm{H} \alpha$ flares. If Ellison's study, in 1953, and our survey of the McMath-Hulbert Observatory flares and SWF's for 1958-1961 are correct, then (a) $\mathrm{H} \alpha$ flares of importance 52 without ionizing radiation are rare, and (b) disturbances of the ionosphere can be detected with present ground-based instrumentation for 40 to 50 per cent of all flares of area $>100$ millionths of the solar hemisphere (importance $>1$ ).

\subsection{Study of Short-Wave Fades Associated with all Flares, Importance 3 and 3+, IG Y-1961}

Are great $\mathrm{H} \propto$ fiares generally associated with severe ionospheric disturbances?

Study of ionospheric data for the times of all flares of importance 3 and $3+$ during the 
TABle 6. Magnitude of SHORT-WAVE fades associated WTth flares, IMP. 3 AND $3+$ IGY THROUGH 1961

\begin{tabular}{cccccc}
\hline & $\begin{array}{c}\text { Number of } \\
\text { flares } \\
\text { imp. 3 \& 3+ }\end{array}$ & \multicolumn{3}{c}{ Importance of associated SWF's } & $\begin{array}{c}\text { Number without } \\
\text { confirmed } \\
\text { SWF's }\end{array}$ \\
\hline IGY & 39 & 26 & 8 & 2 & 3 \\
1959 & 30 & 11 & 11 & 4 & 4 \\
1960 & 20 & 11 & 7 & 2 & 0 \\
1961 & 9 & 7 & 1 & 1 & 0 \\
\hline Total & 98 & 55 & 27 & 9 & 7 \\
\hline
\end{tabular}

TABLE 7. List OF GREAT FLARES, IGY THROUGH 1961, WITHOUT CONFIRMED SWF, IMPORTANCE $>2 \mathrm{NN}$ CRPL LISTS

\begin{tabular}{|c|c|c|c|c|}
\hline \multicolumn{5}{|c|}{ Flares of imp. $3 \pm$ with no SWF in CRPL lists } \\
\hline Date & Time & Max. & Position & Remarks \\
\hline 1957 Nov. 29 & $0045-0600$ & 0213 & N41E63 & $\begin{array}{l}\text { Flare reported by Sydney only, with type II } \\
\text { burst. Also large event at } 9500 \text { Mc. }\end{array}$ \\
\hline 1958 Mar. 5 & $0500-0632$ & 0540 & S12E46 & $\begin{array}{l}\text { Flare reported by Alma Ata only, with micro- } \\
\text { wave burst of } 5 \text { minutes duration. }\end{array}$ \\
\hline 1958 Sept. 18 & $0728-0938$ & 0830 & S11W53 & $\begin{array}{l}\text { With SEA of imp. } 2 \text {, and microwave burst of } 10 \\
\text { minutes duration. }\end{array}$ \\
\hline 1959 Jan. 26 & $1027-1315$ & 1050 & N16W61 & With great burst at $2980 \mathrm{Mc}$, and SEA of imp. \\
\hline $\begin{array}{l}1959 \text { Feb. } 18 \\
1959 \text { Feb. } 18\end{array}$ & $\begin{array}{r}1005-1020 \\
1142-1150\end{array}$ & & $\left.\begin{array}{l}\text { N21E76 } \\
\text { N21E76 }\end{array}\right\}$ & $\begin{array}{l}\text { Flares reported by Kanzelhohe only. Many other } \\
\text { stations were observing the Sun at these times } \\
\text { and do not report these events. }\end{array}$ \\
\hline 1959 May 9 & $0123-0212$ & 0150 & N20E78 & $\begin{array}{l}\text { No reported radio frequency events with flare, } \\
\text { reported by Sydney only. }\end{array}$ \\
\hline \multicolumn{5}{|c|}{ Flares of imp. $3 \pm$ with SWF's of Imp. $1 \pm$} \\
\hline 1958 Feb. 9 & $08-2302$ & & & $\begin{array}{l}\text { Flare is followed by major type IV event, PCA, } \\
\text { and great magnetic storm. }\end{array}$ \\
\hline 1958 May 1 & $2115-2241$ & 2130 & S18E15 & $\begin{array}{l}\text { With modest rise and fall at } 2800 \mathrm{Mc} \text {, of duration } \\
>3 \text { hours. }\end{array}$ \\
\hline 1959 Feb. 2 & $1017-1225$ & 1039 & N22W30 & $\begin{array}{l}\text { No known radio frequency events with this } \\
\text { flare. }\end{array}$ \\
\hline 1959 Feb. 19 & 2032-2244 & 2037 & N11W10 & $\begin{array}{l}\text { With microwave burst of } 10 \text { minutes duration, } \\
\text { a few small type III's and a noise storm. }\end{array}$ \\
\hline 1959 Mar. 28 & 2113-2315 & 2126 & N24W33 & $\begin{array}{l}\text { With modest microwave burst and weak type } \\
\text { III. Also great magnetic storm in progress. }\end{array}$ \\
\hline 1959 July 27 & $2050-2250$ & 2115 & N27E26 & $\begin{array}{l}\text { With modest } 2800 \mathrm{Mc} \text { rise and fall of } 2 \text { hours } \\
\text { duration, and type II. }\end{array}$ \\
\hline 1960 June 26 & $\underline{0428-0525}$ & 0436 & N20W08 & With microwave burst of 10 minutes duration. \\
\hline 1960 Nov. 6 & $\overline{1752}-\overline{2030}$ & 1841 & N13E07 & $\begin{array}{l}\text { With small } 2800 \text { Mc rise and fall of } 5 \text { hours } \\
\text { duration, and type II. }\end{array}$ \\
\hline 1961 May 4 & $2145-2340$ & 2213 & S10W56 & With dekameter type IV. \\
\hline
\end{tabular}

$4 \frac{1}{2}$ years IGY-1961 gives an affirmative answer to this question (Table 6). Of the 98 flares of importance 3 or $3+$ that occurred in this interval, 84 per cent were accompanied by severe ionospheric disturbances (imp. $>2$ in the CRPL lists). There were only 16 instances in the world-wide data of flares of importance 3 with minor, or no SWF and in the majority of these discordant situations, there is reason to question some aspect of the observational information (Table 7). The seven flares of importance 3 and 3+ without reported SWF's all took place in the first half of the Universal Day. Only two of these flares were reported by more than one observing station and for those two cases, NERA lists enhancements of 
atmospherics of importance 2 and 1 at appropriate times. Of the nine flares of importance 3 and $3+$ with SWF's of importance less than 2 , five reached maximum intensity between $21^{\mathrm{h}}$ and $23^{\mathrm{h}}$ U.T., the portion of the Universal Day in which the detection of SWF's apparently has proved difficult.

\subsection{Factors Affecting the Occurrence of SWF's with Ha Flares}

\section{4(a) Published reports}

Although critical review of the data indicates some form of observational difficulty for the majority of cases of great $\mathrm{H} \alpha$ flares without severe ionization effects, there are enough instances of apparent imbalance to warrant a search for the factors that favor or impede the emission of ionizing radiation at the time of an $\mathrm{H} \alpha$ flare. Davies ${ }^{(6)}$ points out diversity in the ionospheric phenomena as well as apparent lack of relation to the magnitude of the flare. In 1958 Warwick and Wood ${ }^{(7)}$ studied the occurrence of SWF's with 278 flares near the solar limb on flare patrol films at the Sacramento Peak Observatory. They investigated especially, the apparent height of the $\mathrm{H} \propto$ flares, and concluded that (for flares at the limb) there is a "strong positive relation between flare height and SWF production". The relationship is interpreted as an "absorption effect rather than a critical height radiation mechanism". They also point out that there is a strong positive relation between flare intensity and the occurrence of ionospheric disturbances, and that flares with $2800 \mathrm{Mc} / \mathrm{s}$ bursts are particularly likely to be associated with SWF's.

Ellison $^{(8)}$ has continued his excellent studies of the development of $\mathrm{H} \alpha$ flares and associated ionospheric disturbances. He points out that for the flares in his investigation the magnitude of the S.I.D. (sudden ionospheric disturbance) "is determined by the peak intensity of the flare flash and the rapidity with which this is achieved rather than by the flare area".

Studies ${ }^{(7.9)}$ have shown that for each importance category of $\mathrm{H} \alpha$ flares, there is a higher percentage of ionospheric disturbances for flares with accompanying bursts at $2800 \mathrm{Mc} / \mathrm{s}$ than for those without such radio frequency emission. Therefore, it is appropriate to consider as circumstances favoring SWF's, the situations that favor centimeter radiation. Martres and Pick ${ }^{(10)}$ have studied the position of $\mathrm{H} \alpha$ flares with respect to sunspots. According to their investigation, emission at high radio frequencies is determined less by the area of a flare (i.e. importance) than by the position of the flare with respect to spots. They report that even large flares (importance 2) far from spots, and therefore far from magnetic fields, were not accompanied by centimeter radiation. Malville and Smith ${ }^{(11)}$ likewise find that "the percentage of the total umbral area of a sunspot group covered by a flare is related to the intensity of the associated $2800 \mathrm{Mc} / \mathrm{s}$ burst". Covington ${ }^{(12)}$ has pointed out the time coincidence of certain $2800 \mathrm{Mc} / \mathrm{s}$ bursts with the "explosive phase"(13) of flares, and Angle ${ }^{(14)}$ reports that flares with an explosive phase have a higher percentage of association with $2800 \mathrm{Mc} / \mathrm{s}$ bursts and short-wave fades than do flares in general.

At numerous intervals during the last twelve years, Friedman and his associates at the U.S. Naval Research Laboratory have made observations of solar X-ray emission. Their observations show that there is variability not only in the intensity of the solar X-ray flux but also in its spectrum. The first Solar Radiation Satellite, SR-1, provided data on X-ray emission in the 2-8 $\AA$ portion of the spectrum for a large number of brief intervals from July 1-November 15,1960 . On the basis of the SR-1 data Kreplin et al. ${ }^{(15)}$, report that ionospheric disturbances occur when the X-ray flux below $8 \AA$ exceeds $2 \times 10^{-3} \mathrm{ergs} / \mathrm{cm}^{2} / \mathrm{sec}$. Solar X-ray emission in the 8-20 \& band, as recorded on SR-3(June 29-November 26, 
1961), has been studied by Acton et al. ${ }^{(16)}$ They report that at these wavelengths, the relation between $\mathrm{X}$-ray flux and the occurrence of ionospheric disturbances with flares appears to be not as clear-cut as at the shorter X-ray wavelengths. Comparison, by Teske, of the published SR-3 data with the 5 Mc WWV records at the McMath-Hulbert Observatory indicates that when X-ray flux in the 8-20 $\AA$ range exceeded $25 \times 10^{-3} \mathrm{ergs} / \mathrm{cm}^{2} / \mathrm{sec}$ ionospheric absorption was in progress. When the flux was lower than this value and the ionospheric records were satisfactory, absorption was not shown. Kundu ${ }^{(\mathbf{1 7})}$ has pointed out a similarity in time and form between bursts at centimeter wavelengths and concomitant high-energy X-ray bursts.

Fortini $^{(18)}$ has studied groups of similar SCNA and SEA records for 1958 and reports that ionospheric disturbances similar in form and development accompanied $\mathrm{H} \alpha$ flares that repeated in the same part of an active center.

In 1955, on the basis of photometric measurements of 194 flares and subflares, and of currently available ionospheric data, Dodson et al. ${ }^{(\mathbf{1 9 )}}$, reported that maximum $\mathrm{H} \alpha$ flare intensity of the order of 0.8 of the local continuum was both necessary and sufficient for the occurrence of a concomitant ionospheric disturbance. Area appeared to be less significant than intensity in distinguishing between flares with and without ionospheric disturbances. However, for a high proportion of the flares studied, areas as great as $\mathbf{2 0 0}$ millionths of the solar disk were sufficient for the occurrence of ionospheric disturbances.

\section{4(b) Special examination of $\mathrm{H \alpha}$ records}

Photometric material of a similar nature is not available for study of flares in the recent maximum. Nevertheless, the filtroheliograms of the McMath-Hulbert Observatory flare patrol tend to confirm the earlier photometric work. The records indicate, primarily, a close relationship between the onset and development of $\mathrm{H} \alpha$ flares and associated ionospheric disturbances, provided that the ionospheric recorder is well adjusted and is not disturbed by geomagnetic storms, the flare is not so close to the limb that the normal development of the $\mathrm{H} \alpha$ flare is hard to follow, and the magnitude of the $\mathrm{H} \alpha$ event is not overestimated because of large area but relatively low intensity.

The McMath-Hulbert Observatory flare patrol films for 1958-1961, contain no examples of flares of importance $>3$ without accompanying ionospheric disturbances. They do contain records for three of these great flares for which associated short-wave fades were evaluated at CRPL as of only importance $1+$. In addition, there are records of four flares reported as of importance 2 and a small number of flares of importance $1+$, which occurred during times when our ionospheric record was reliable, and for which there is no concomitant ionospheric disturbance. The $\mathrm{H} \alpha$ records of these flares without commensurately great ionospheric disturbances, show that the flares tended to consist of many small parts, often closely associated with filaments and absorbing material. The main body of the flare was far from major spots and the intensity was relatively low. The rise to maximum was slow and the accompanying centimeter radiation not great. The four flares of importance $2 \pm$, without ionospheric disturbances are:

\begin{tabular}{lllll} 
28 Oct., 1958 & Start End & Max. & & \\
22 Nov., 1958 & $\underline{1647}-1602$ & 1514 & N20 & W40 \\
30 July, 1959 & $1648-1850$ & 1704 & S14 & E65 \\
8 Sept., 1961 & $\underline{1445}-1710$ & 1518 & N28 & W11 \\
\hline
\end{tabular}


The foregoing investigations indicate that strong $\mathrm{H} \alpha$ intensity, sudden rise to maximum, proximity to spots, and strong centimeter radiation favor the occurrence of severe ionospheric disturbances. Lest these characteristics be taken as necessary circumstances for the emission of ionizing radiation with flares, attention should be directed to two flares that took place on successive days in the same plage:

$$
\begin{array}{llllll}
\text { 13 July, 1959 } & \text { Start End } & \text { Max. } & & & \\
\text { 14 July, 1959 } & \underline{1920}-2210 & 2016 & \text { imp. 2 } & \text { S23 } & \text { E48 } \\
\hline & \underline{1730} & 1445 & \text { imp. 3 } & \text { S25 } & \text { E37 }
\end{array}
$$

Both of these flares rose to maximum slowly and were large but not especially intense. On July 13, according to our records, there was only one very small spot in the plage and on the 14th there was none. Nevertheless, both flares were accompanied by well-confirmed ionospheric disturbances of importance 2 and $2+$ respectively. Both of the ionospheric disturbances developed slowly and seemed to follow the relatively slow rise to maximum of the $\mathrm{H} \alpha$ flare. On the 14th, there was no enhancement of $10 \mathrm{~cm}$ radiation until close to flare maximum and more than forty minutes after the start of the flare and short-wave fade.

It may be possible in years ahead, when ionospheric specialists have secured extensive, well-calibrated world-wide data, to identify with confidence the aspects of flares that lead to especially strong ionizing radiation. At the present time when the simple ionospheric records (SWF or SEA) and flare data are satisfactory, there is evidence for the occurrence of ionospheric disturbances of these types with approximately 46 per cent of the $H \alpha$ flares with area $>100$ millionths of the solar hemisphere (importance $>1$ ), and with practically all of the flares of average intensity and area $>250$ millionths of the solar hemisphere (importance $>2$ ). Close study of the records constantly suggests that increased precision in the ionospheric records would reveal a much greater number of small, flare-associated ionospheric disturbances and reduce the magnitude of the $\mathrm{H} \alpha$ events with which ionizing radiation can be detected by ground-based equipment.

\subsection{Study of Solar Events Associated with All Short-Wave Fades of Importance 3 \pm , 1957-1961}

Are great ionospheric disturbances generally associated with important solar flares?

To try to answer this question we have examined, in detail, solar data associated with the 204 well-confirmed short-wave fades of importance $3 \pm$ which occurred in the five years 1957-1961 (Table 8). Before starting the investigation, forty SWF's listed as of importance $3 \pm$ by CRPL were excluded from the study because of lack of certainty in the data: 28 because the SWF was reported by only one station, had low "wide-spread-index", or very short duration; 12 because observation of the apparently associated flare was too fragmentary to be meaningful.

For 151 of the 204 well-confirmed great short-wave fades, association with "great" $\mathrm{H} \alpha$ flares (imp. 2 or 3) was easy and obvious. Another 24 cases occurred in time association with flares $560^{\circ}$ from the center of the solar disk and for which the importance was called only $1 \pm$. As previously pointed out, for flares more than $60^{\circ}$ from the center of the solar disk, the assigned importance is often a poor guide to the magnitude of the event that has taken place on the Sun.

\section{5(a) Severe ionospheric disturbances with limb events}

It is of especial interest that eight of the great SWF's were at the time of "important" bright surges and/or loop-type prominences at the limb of the Sun but without reports of even minor 
TABLE 8. Importance of H $\alpha$ flares assoctated with 204* SWF's of IMPORTANCE 3土, 1957-1961

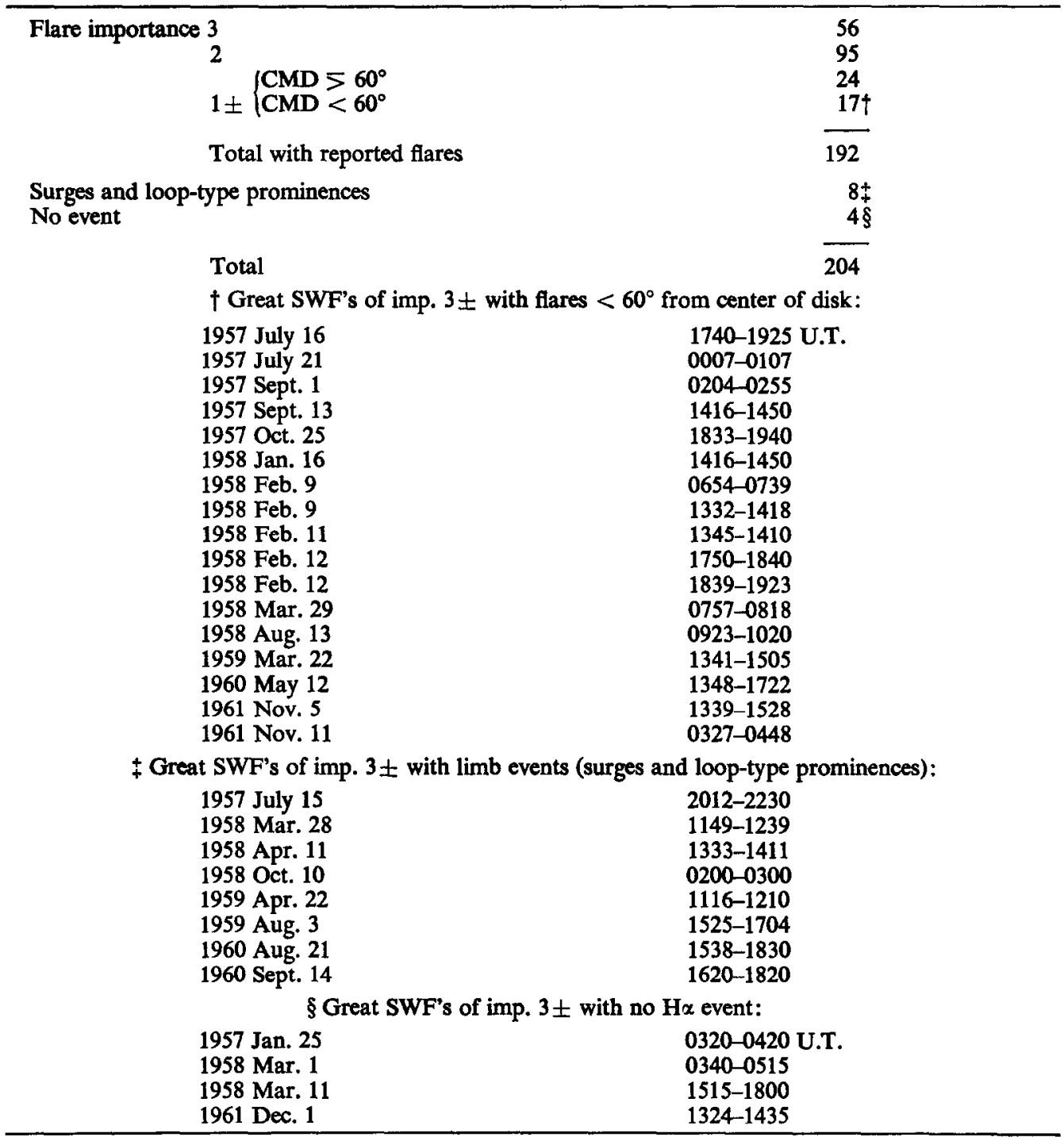

* Forty cases have been omitted from the study because of uncertainty in some aspect of the data.

flares on the adjacent disk. The association of ejections with the beginning of ionospheric disturbances and of loop-type prominences with their later phase is in complete accord with observational experience at the McMath-Hulbert Observatory. Since it is possible that events of this type can provide critical data relating to the complex flare phenomenon, we bring together data for one of them: 14 September 1960, 1620-1830 U.T.

The short-wave fade began gradually at 1620 U.T. and lasted until at least 1830 U.T. It was reported by many stations and all agree that the disturbance was severe. No phenomenon of the kind usually reported as flare or subflare was in progress when the SWF began and none was reported until an hour later. The flare patrol film shows that prominence activity had been taking place during preceding hours at $\mathrm{S} 17^{\circ} \mathrm{E} 90^{\circ}$. A distinct change in 
this activity occurs at $1614 \pm$ U.T. Two features that resemble ejections or surges are photographed. They are still visible at 1627 U.T., but not later. At about 1722 U.T. a small bright dot appears above the region. It becomes as bright as many disk flares and is reported as a flare (importance 1). After 1735 U.T. it fades in intensity and the phenomenon develops into a system of loop-type prominences which were still visible as late as 2000 U.T. The ionospheric disturbance began during the apparent ejection in the region and was in progress for almost an hour before any feature of flare brightness was observed. Furthermore, enhancements at radio frequencies did not occur until 1703 and 1704.5 U.T. when, at 2800 and $9100 \mathrm{Mc}$ respectively, there were bursts of six and two minutes' duration with peak flux of 19 and $165 \times 10^{-22} \mathrm{~W} / \mathrm{m}^{2} / \mathrm{c} / \mathrm{s}$. These radio frequency events took place approximately forty minutes after the start of the ionospheric disturbance. Dynamic spectrum observations were in progress and the only event reported was a group of type III bursts, 1758-1802 U.T., which is close in time to the start and maximum of a small flare in another part of the disk.

\section{5(b) Severe ionospheric disturbances with minor Ha flares on the disk}

Of the 204 short-wave fades of importance $3 \pm$ there remain twenty-one cases of apparent serious imbalance between the short-wave fade and the $\mathrm{H} \alpha$ flare. The dates of these SWF's are listed in Table 7. It is possible that the importance of certain of these flares has been underestimated or that the flare emission may have been especially rich in ionizing radiation. Three of the flares are known to have been over and/or very close to major umbrae and accompanied by type IV radiation. For four other flares in the group, individual observers gave importance estimates as great as 2 . Four of the events occurred during severe geomagnetic storms and for the two cases that we can check, the reported ionospheric phenomena coincided with severe geomagnetic changes. These events plus additional examples in September, 1963, indicate that at the beginning of certain geomagnetic disturbances there are sudden, severe ionospheric disturbances that are so similar at different stations that they can be mistaken for the usual flare-associated ionospheric disturbance.

The three cases November 5, November 11 and December 1, 1961 are especially interesting. They took place in the weeks following the detonation of major nuclear devices in the atmosphere. The only known flares are in poor time-association, and concomitant radio frequency events were not reported. The short-wave fades occurred during intervals when relatively minor geomagnetic disturbances were associated with large absorption phenomena on the $18 \mathrm{Mc} / \mathrm{s}$ riometer at the McMath-IIulbert Observatory. One wonders if these three cases (and several others of lesser magnitude in the same time interval) did not reffect special characteristics of the ionosphere at that time.

\section{5(c) Summary}

Finally, according to our survey, 184, or 90 per cent of all well observed SWF's of importance $3 \pm$ from 1957 to 1961, occurred during (a) flares of importance 2 or 3 , (b) flares of importance $1 \pm$ more than $60^{\circ}$ from the center of the disk, or (c) important surge or loop-type prominences at the limb. For these SWF's the concomitant Ha observations are not inconsistent with the occurrence of major flares on the Sun.

\section{H $\alpha$ FLARES AND GEOMAGNETIC DISTURBANCES}

Geomagnetic data in the form of indices and reports of individual storms are so abundant and so fine that those who seek to evaluate the geomagnetic effects of fiares could 
hardly ask for more information. Unfortunately geomagnetic disturbances or storms are considered to be of at least two kinds, sporadic and recurrent, and the two types are not always readily distinguishable. The former occur most frequently during times of high solar activity, are often classified as sudden commencement (SC) and are usually thought to be flare-associated. Recurrent storms are most easily identified during the declining phase of the solar activity cycle, are usually not classified as SC, and often take place without obvious antecedent flare activity. The distinction between sporadic and recurrent storms must usually be made on the basis of the existence of repeated time intervals between storms of the order of 27 days, even though this process may inadvertently include flareassociated storms separated by approximately 27 days. Studies by Saemundsson ${ }^{(20)}$, Bell(21) and our own comparisons of flare and geomagnetic data provide evidence for geomagnetic disturbances similar to recurrent storms near times of great solar activity as well as during the declining phase of the 11-year cycle. If this is the case, it adds more confusion to the recognition of storm-causing flares.

\subsection{Number of Geomagnetic Storms}

During the $4 \frac{1}{2}$ year interval from the start of the IGY to the end of 1961, 253 geomagnetic storms were reported by at least two stations, according to data summarized by $V$. Lincoln in the Journal of Geophysical Research. Of these, 117 were considered to be SC by the majority of reporting stations. For 15 storms, the stations divided evenly between SC and non-SC. For the remaining 121 storms the majority of reporting stations denied

Table 9. Geomagnetic Storms* IGY to 1961. Based on Reports of INDIVIDUAL STATIONS PUBLISHED BY V. LINCOLN IN J.G.R.

\begin{tabular}{|c|c|c|c|c|c|}
\hline $\begin{array}{l}\text { Severe } \\
\text { storms }\end{array}$ & $\begin{array}{c}\text { IGY } \\
\text { (July } 11957- \\
\text { Dec. } 31 \quad 1958 \text { ) }\end{array}$ & 1959 & 1960 & 1961 & Total \\
\hline SC & 4 & 2 & 2 & 2 & 10 \\
\hline & - & $\ldots$ & 1 & - & 1 \\
\hline $1 / 2 \mathrm{sC}, 1 / 2 \mathrm{~g}$ & 一 & - & 1 & - & 1 \\
\hline Totals & 4 & 2 & 4 & 2 & 12 \\
\hline \multicolumn{6}{|c|}{ Moderately severe storms } \\
\hline SC & 24 & 15 & 16 & 8 & 63 \\
\hline & 15 & 13 & 9 & 21 & 58 \\
\hline $1 / 2 \mathrm{SC}, 1 / 2 \mathrm{~g}$ & 4 & 2 & 2 & 0 & 8 \\
\hline Totals & 43 & 30 & 27 & 29 & 129 \\
\hline \multicolumn{6}{|c|}{ Moderate storms } \\
\hline SC & 17 & 9 & 8 & 10 & 44 \\
\hline g & 22 & 15 & 17 & 8 & 62 \\
\hline $1 / 2 \mathrm{SC}, 1 / 2 \mathrm{~g}$ & 4 & 1 & 0 & 1 & 6 \\
\hline Totals & 43 & 25 & 25 & 19 & 112 \\
\hline Total SC & 45 & 26 & 26 & 20 & 117 \\
\hline Total $\mathbf{g}$ & 37 & 28 & 27 & 29 & 121 \\
\hline Total $1 / 2 \mathrm{SC}, 1 / 2 \mathrm{~g}$ & 8 & 3 & 3 & 1 & 15 \\
\hline Grand totals & 90 & 57 & 56 & 50 & 253 \\
\hline
\end{tabular}

* Excludes storms reported by one station only. 
occurrence of a sudden commencement (Table 9). During the same interval, according to reports to the Quarterly Bulletin of Solar Activity and the McMath-Hulbert Observatory Working Lists of Flares, there were more than 13,000 flares of importance $>1$, including $\sim 950$ flares of importance $>2$. If it is true that sporadic and/or sudden commencement storms are a consequence of particle ejection at the time of specific flares, then it is clear that some aspect other than size and brightness of the $\mathrm{H} \alpha$ flare must be sought if the stormcausing aspect of the flare is to be recognized.

\subsection{Identification of Flares. Associated with Subsequent Geomagnetic Storms}

In recent years many studies have been directed towards finding this distinguishing characteristic in the flare-associated emission at radio frequencies. Studies have been made of the storm association of flares with concomitant slow drift bursts, type $\mathrm{II}^{(22,23)}$; with continuum radiation, type $\mathrm{IV}^{(24-30)}$; with emission at dekametric wavelengths ${ }^{(31)}$; with strong bursts at meter wavelengths in the premaximum phase of the $\mathrm{H} \alpha$ flare $^{(32)}$, or with metric bursts at any time during the flare ${ }^{(33)}$. These various types of radio-frequency emission are not mutually exclusive phenomena and all of the studies have shown that the probability of subsequent geomagnetic storms increases for flares with these special types of radio-frequency emission. The studies also agree in indicating that important $\mathrm{H} \propto$ flares without such enhanced radio-frequency emission generally are poor storm producers.

The differentiation between $\mathrm{H} \alpha$ flares on the basis of concomitant radio-frequency emission has improved greatly the statistical relationships between flares and subsequent geomagnetic phenomena. In spite of this progress, the identification of specific stormproducing flares still is far from sure because of the great richness of solar activity, and the relatively long travel time from Sun to Earth of storm-causing particles. Often there are numerous flares with possible storm-producing characteristics in the critical one-to-three days prior to the onset of a geomagnetic storm.

In the study by DeFeiter et al. ${ }^{(27)}$, of major solar radio events and subsequent geomagnetic storms, this basic problem is clearly stated. They write: "Every identification of the solar process responsible for a geomagnetic storm is, to some extent, tentative. ... The different solar phenomena all have a tendency to occur during the same periods, when solar activity is on a high level. During such periods there is a fair chance that the solar phenomenon $X$, which brings on a geomagnetic storm, will occur. In this case there is also an enhanced probability of occurrence of other primary phenomena, $A, B$, etc.... The only relevant procedure is to compare several superposed epoch diagrams pertaining to different categories of events".

This is the approach to the problem undertaken by the extensive statistical studies by Bel1 ${ }^{(21,34)}$. These investigations illustrate the degrees of association that exist, statistically, in current world-wide data between the onset of geomagnetic storms of various degrees of severity and precedent types of solar activity, great $\mathrm{H} \alpha$ flares (in spot groups of different magnetic types, north and south etc.), type II bursts with and without type IV and/or flares, type IV bursts with and without type II etc. (Table 10).

In the 1961 paper Bell(54) reports that the flares associated with great geomagnetic storms showed the expected concentration toward the central part of the solar disk, an unexpected concentration in the northern hemisphere, and a closer association between storms and major $\mathrm{H} \alpha$ flares in regions with magnetically complex spots $(\gamma$ or $\beta \gamma)$ than with similar fiares in unipolar $(\alpha)$ or bipolar $(\beta)$ regions. In the 1963 study $^{(21)}$, the author summarizes the results as follows: "The data clearly indicate a very strong association between 


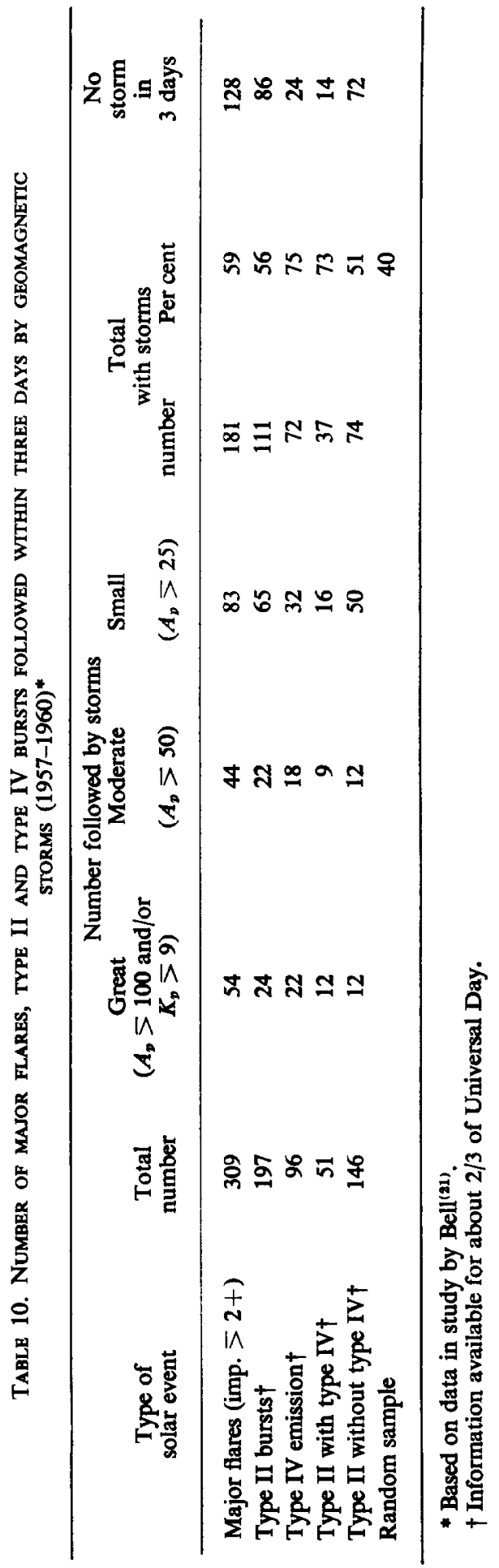


radio bursts of spectral type IV and great geomagnetic storms. The success of a type II burst appears to depend on the presence of a Type IV. Type II bursts that are unaccompanied by type IV are significantly related only to small storms. However, type IV and type II bursts occurring together give the highest probability of a great storm. Type IV events lasting less than fifteen minutes are unlikely to be followed by more than a small storm". The above study associates 76 per cent of the 96 known type IV bursts of 19571960 with a subsequent geomagnetic storm.

TABLE 11. TyPe IV EMISSION AND geOPHYSICAL PHENOMENA (1957-1961)

\begin{tabular}{|c|c|c|c|c|c|c|}
\hline \multirow{2}{*}{$\begin{array}{l}\text { Number and magnitude } \\
\text { of type IV event }\end{array}$} & \multirow{2}{*}{ Duration } & \multirow{2}{*}{$\begin{array}{c}\text { Total } \\
\text { number }\end{array}$} & \multicolumn{3}{|c|}{$\begin{array}{l}\text { Number of subsequent } \\
\text { geophysical events }\end{array}$} & \multirow{2}{*}{$\begin{array}{l}\text { Number } \\
\text { without } \\
\text { storms }\end{array}$} \\
\hline & & & PCA & $\begin{array}{l}\text { Geomagnetic } \\
\text { storms in } \\
3 \frac{1}{2} \text { days }\end{array}$ & $\begin{array}{c}\text { SC } \\
\text { storms in } \\
3 \frac{1}{2} \text { days }\end{array}$ & \\
\hline Very large & & 14 & 7 & 14 & 11 & 0 \\
\hline Large & $>1$ hour & 10 & 7 & 8 & 6 & 2 \\
\hline Moderately large & & 29 & 13 & 28 & 21 & 1 \\
\hline \multirow[t]{2}{*}{ Small } & $<1$ hour & 63 & 9 & 47 & 31 & 16 \\
\hline & Total & 116 & 36 & 97 & 69 & 19 \\
\hline
\end{tabular}

At the McMath-Hulbert Observatory we have examined the detailed geomagnetic indices and reports of storms for 1957-1961. The results are summarized in Table 11. They confirm the close association between long duration Type IV and subsequent onset of geomagnetic storms and most especially the occurrrence of the Sudden Commencement phenomenon.

\subsection{Some Characteristics of $\mathrm{H} \alpha$ Flares Associated with Type IV Radiation andlor Subsequent Geomagnetic Storms}

The close association between type IV emission and geomagnetic storms makes it appropriate to seek characteristics of storm-producing flares through study of flares accompanied by this form of radio-frequency emission. Figure 3 gives the importance and disk distribution of the 113 flares in the five-year interval 1957-1961, known to have emitted type IV radiation (from reports of dynamic spectra). The flares not followed by a geomagnetic disturbance in $3 \frac{1}{2}$ days have been separated from the storm-associated events.

Two thirds of the "type IV flares" were of importance $>\mathbf{2}$ and, once again, there emerges from the data the familiar pattern of association between centrally-located important $\mathrm{H} \alpha$ flares and subsequent geomagnetic storms.

$\mathbf{H} \propto$ spectroheliograms yield additional characteristics of flares with type IV emission at radio frequencies. First, according to our records, flares with strong, long-enduring type IV radiation usually have shown a portion of the $\mathrm{H} \alpha$ emission over a major spot umbra ${ }^{\text {(35). }}$. The significance of proximity of the $\mathrm{H} \alpha$ flare to major umbrae and/or strong magnetic fields is not clear. Since the covering of umbrae by flares occurs more often in the late stages than in the early phases of flares, it probably reflects consequences rather than causes or may indicate circumstances that permit the spreading of the flare to regions of high magnetic field. Flare emission over a major umbra is a relatively infrequent circumstance. According to a study by Wolbach ${ }^{(36)}$ about one-fourth of the flares of importance $>2$ in eleven centers 
50

Large Type II Events

With Storms

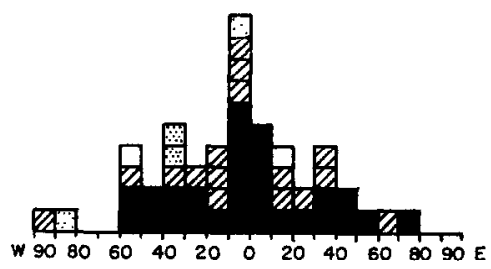

3 Large Type II Events

Without Storms

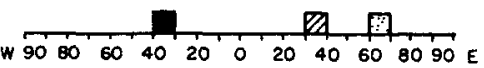

47 Small Type II Events

With Storms

(1) With No Known Flare)

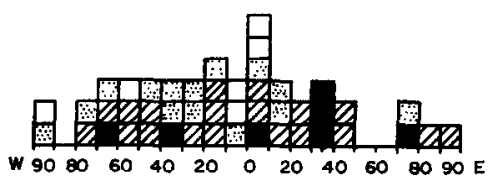

16 Small Type II Events

Without Storms

(2 With No Known Flare)

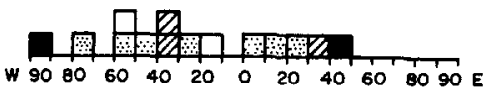

Flare importence: $\square$ 1. $\quad$ I or $1+\square$ or $2+\square 3$ or $3+$

Fig. 3. Disk DISTRIBUTION, IMPORTANCE AND STORM ASSOCIATION OF FLARES WITH TYPE IV EMISSION AT RADIO FREQUENCIES.

of activity extended over major umbrae. Secondly, our observations indicate that great systems of loop-type prominences have developed in the post-maximum phase of important $\mathrm{H} \propto$ flares with portions over major umbrae and with strong, long enduring type IV radiation. The systems of loop-type prominences have been observed with flares at the limb and on the $\operatorname{disk}^{(37)}$.

Martres and Pick ${ }^{(38)}$ report that flares associated with type IV emission and increases of noise storm activity on metric wavelengths occur close to the positions of filaments within centers of activity, "the facular filaments". Furthermore, for the cases of especially intense bursts of type IV radiation, the flares formed "bright lines" each covering a group of spots of the same polarity.

That important $\mathrm{H} \alpha$ flares covering the umbrae of major spots may be storm-producing flares, is supported by Dr. Hale's fine spectroheliograms ${ }^{(39)}$ of flares that preceded eight very great and four moderately great geomagnetic storms (1892-1926). Insofar as one can tell from spectroheliograms alone, all but one of these great storm-producing flares showed a portion of the flare emission directly over a major spot. The large flare on 10 May, 1949,

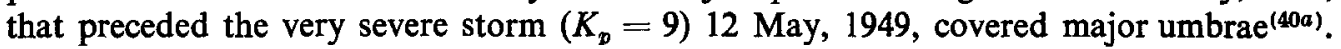
However, the same was true of the similar flare of 8 May 1949, which was followed by an "SC" and only a small storm early on 11 May. Within the limitations of available observational material, all $\mathrm{H} \alpha$ flares known to have been associated with ground-level cosmic ray events $^{(41)}$, and with the more severe proton (PCA) events ${ }^{(42)}$, have had emission portions superposed over major umbrae. To the extent that these flares have been followed also by geomagnetic storms, they contribute to the association between flares over major umbrae and subsequent disturbances of the Earth's magnetic field.

Conversely, two major flares in the great center of activity in May, 1951, which was "notorious" for having failed to produce geomagnetic disturbances, lacked the two optical 
attributes here described for flares with type IV radiation and storm association. A major flare occurred when the region was at the east limb (8 May 1951)(40b). Although cxtensive prominence activity accompanied the event, a great system of loop-type prominences did not develop. Furthermore the large, bright flare (imp. 3) that took place in the region $\left(\mathrm{N}^{\circ} 2^{\circ} \mathrm{W} 43^{\circ}\right)$ on 19 May avoided major umbrae throughout its development ${ }^{(40)}$. Since flares in the same region tend to recur in similar locations, it is possible that the flares in this nonstorm-producing region tended to avoid major umbrae.*

\subsection{Storms Preceded by Flares with Type IV Radiation}

In view of the apparently close association between flares with type IV radiation and subsequent geomagnetic storms, the proportion of geomagnetic storms preceded by fiares with such radiation is disappointingly low (Table 12). The disparity remains even if the known cases of storms preceded by type IV emission be increased by 50 per cent to allow for limitations in the observational data (dynamic spectra) relating to type IV radiation. It is only for the great geomagnetic storms that the type IV-associated-flares account for a large proportion of the events. This problem is recognized by DeFeiter et al. ${ }^{(27)}$, who on the basis of the almost complete 24-hour patrol at 200, 545 and $3000 \mathrm{Mc} / \mathrm{s}$ from April 1957-December 1959, report that "about one-half of the geomagnetic storms cannot be related to a particular radio outburst of great magnitude" (generally belonging to type IV) during the preceding $60 \mathrm{hr}$, the time limit used by the Dutch investigators.

It should be borne in mind that storms following flares near the central part of the disk tend to be more severe than storms associated with flares closer to the solar limb, and that type IV radiation is observed primarily with important $\mathrm{H} \alpha$ flares near the central part of the disk. Accordingly, the high central concentration of flares selected on the basis of type IV radiation may be an important factor contributing to the close association between strong geomagnetic storms and type IV radiation. Association of type II bursts with the ejection of storm-producing particles should not be disparaged because the subsequent storms are often of only moderate severity, especially since the associated $\mathrm{H \alpha}$ flares are often of relatively low importance or are far from the center of the solar disk.

\subsection{Severe Geomagnetic Storms without the Usual Types of Precedent Flare Activity}

Even among the lists of exceedingly severe geomagnetic storms there are cases, albeit few in number, for which the evidence of flare-association is not convincing. During the years of great solar activity it is seldom difficult to find reports of flares two or three days prior to the onset of a geomagnetic storm, but the assignment of storm causation to any one of these flares sometimes seems arbitrary and hard to justify. The problem is well illustrated by examination of Bartel's list of all geomagnetic disturbances with $K_{p}$ as great as 9 in the thirty years, 1932-1962(43). There are only 37 storms in the list. Seventeen took place after 1 January, 1957 and of these, fourteen are known to have been preceded by proton events (Polar Cap Absorption). One additional case was preceded by a flare, imp. $1+$, $S O 8^{\circ} \mathrm{E} 84^{\circ}$, with type II radio-frequency emission. For the two remaining cases, 5 October 1960 and 28 October 1961, there are no reports of major flares, short-wave fades, or major radio-frequency events within suitable preceding time intervals. It is possible that these

* In contrast, the active region with CMP 20 September 1963, had flares with loop-type prominences at east and west limbs and on the disk, and with portions over major umbrae. This region was associated with severe geomagnetic storms and disturbances. Both the May 1951 and September 1963 regions were late in the solar cycle. 


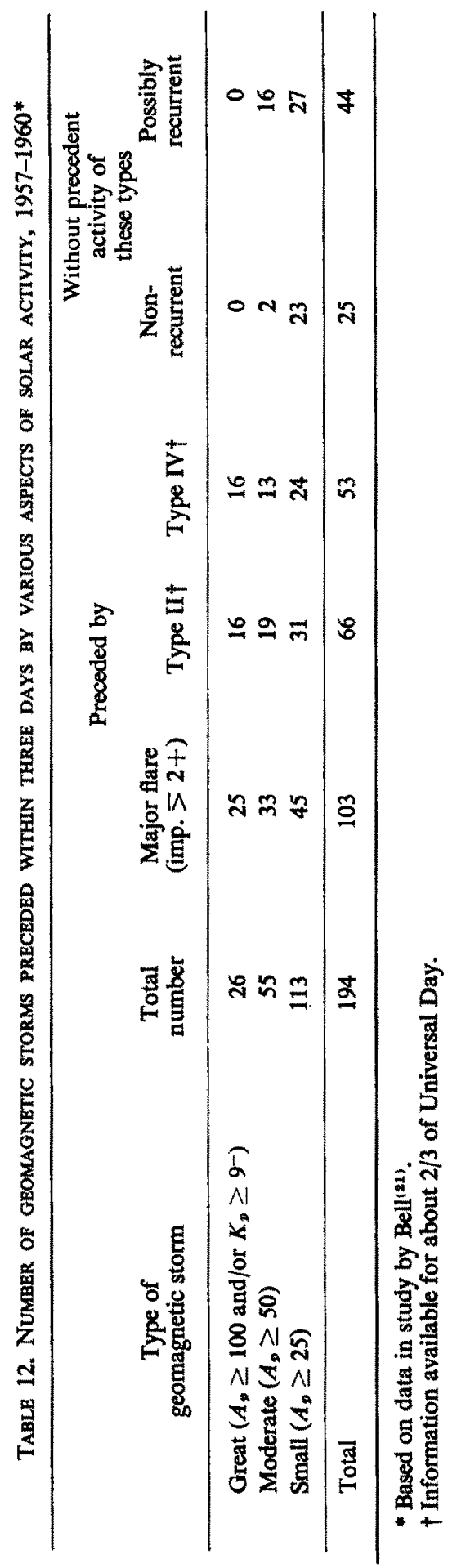


two storms constitute a warning that the cause of severe geomagnetic storms, even of the apparently sporadic type or with SC's, may not always rest with the seemingly suitable precedent flares that we currently associate with them.

Since so many of the storms with $K_{p}$ as great as 9 appear to have been associated with solar proton events, it may be significant that both "problem" storms, 5 October 1960 and 28 October 1961, took place at the time of central meridian passage of regions that had been the sites of proton flares in the preceding rotation. The 5 October 1960 , storm coincided with the central meridian passage of the region with the cosmic ray flare at the east limb on 3 September 1960. There was no geomagnetic disturbance when this region crossed the central meridian in September. The great 28 October 1961, storm was 28 days after the 30 September storm and was coincident with the October central meridian passage of the region with the proton event of 28 September 1961. This later circumstance has been noted previously by Bryant et al. ${ }^{(44)}$, who also report a similar association for the geomagnetic storm of 1 December 1961. For the preceding solar cycle, Dr. Bartel's list of K-9 storms includes two events, 25 September 1951 and 28 October 1951 for which our records provide no obvious flare association. These storms took place at a phase of the 11-year activity cycle similar to that of the "problem" storms considered above.

Do geomagnetic storms generally occur during the next rotation of a region associated with proton flares? In the five years 1957-1961 there were 34 regions with proton events. In fifteen instances geomagnetic storms occurred when the region that had been the site of a proton flare crossed the central meridian in the next rotation. For at least thirty of the regions there were geomagnetic storms at some time during the rotation following the proton events. For many of these storms individual flares easily could have been the source of the storm particles, but in other instances, flare association is not clear.

\section{CHARACTERISTICS OF FLARES ASSOCIATED WITH POLAR CAP ABSORPTION}

In recent years great interest has centered in the emission of high-energy particles and the occurrence of polar cap absorption (PCA) in close time-association with certain solar flares. Many investigators have identified and studied the flares most probably responsible for each case of PCA. In general the studies agree that the high-energy proton ejections have taken place during important $\mathrm{H} \alpha$ flares that were accompanied by strong, longduration continuum radiation (type IV) at radio frequencies. Individual investigators have emphasized different aspects of the type IV radiation that accompanied PCA flares. For example, Avignon and Pick-Gutman ${ }^{(5)}$ point out association with intense bursts at decimeter wavelengths; Kundu and Haddock ${ }^{(46)}$ emphasize the broad-band character of the accompanying centimeter radiation; Thompson and Maxwell(47) indicate association with broad-band continuum in the metric range; Reid and Leinbach ${ }^{(48)}$ and Warwick and Haurwitz ${ }^{(31)}$ lay special importance on enhanced radiation in the dekametric range. The latter authors' summary of their study of flares associated with proton events states, "Emission of solar protons, as detected in polar-cap absorption events, is strongly associated with exceptionally intense and long-lasting solar emission at optical and radio wavelengths. Intensity of the absorption event increases with magnitude of the solar event. These relations tend to become stronger with increasing wavelengths, being weakest for optical flares, and strongest for dekametric radio bursts".

In $1960^{(49)}$ we pointed out that for PCA flares the maximum of the associated $10 \mathrm{~cm}$ emission tends to occur after the maximum of the $\mathrm{H} \alpha$ flare. This characteristic has been exhibited by subsequent PCA flares. In the five years 1957-1961 there were 74 flares with 
$10 \mathrm{~cm}$ radiation $5500 \times 10^{-22} \mathrm{~W} / \mathrm{m}^{2} /(\mathrm{c} / \mathrm{s})$ and with known times of maximum for both the $\mathrm{H} \alpha$ and radio frequency event. For only 21 did the $10 \mathrm{~cm} / \mathrm{s}$ maximum follow $\mathrm{H} \alpha$ maximum and of these, 19 were PCA flares.

Obayashi's fine study(50) of PCA flares, July 1957-December 1960 , brings together many of the solar and geophysical aspects of the solar proton events and emphasizes the time relationship of the phenomena.

Although proton flares generally have been important $\mathrm{H} \alpha$ events with type IV emission, only one-third of the 104 flares of importance 3 and 3+ in the five years 1957-1961 were followed by PCA, and only one-third of the 123 flares with type IV radiation, in the same time interval, were proton flares. In June 1961, at a meeting called by NASA at the High Altitude Observatory of the University of Colorado, we pointed out that the then known PCA flares had occurred primarily in calcium plages in their second or later rotations. According to our records, the subsequent years have failed to provide instances of major proton events with flares in calcium plages in their first rotation. The "maturity" of an active center apparently is playing some part either in the ejection of high-energy particles at the time of great flares or the arrival of the particles in the neighborhood of the Earth.

The major PCA flares, along with other flares associated with strong type IV emission, have included some portion of the $\mathrm{H} \alpha$ flare over the umbra of a relatively large spot. Ellison et $_{\text {al. }}{ }^{(41)}$, in their study of ten flares associated with ground level enhancements of cosmic rays, write that the flares showed "twin bright filaments crossing the spot group and running parallel to the 'magnetic axis', and obscuration of the umbrae with highest field strengths". This is similar to the report of Martres and Pick ${ }^{(38)}$ for flares with intense type IV radiation.

\section{CHARACTERISTICS OF REGIONS IN WHICH PROTON FLARES HAVE OCCURRED}

Efforts to recognise distinctive characteristics of flares associated with PCA may be assisted by studying the regions in which these flares have taken place.

In a recent paper Avignon, Martres-Tropé and Pick-Gutmann ${ }^{(51)}$ report that the spot groups in which PCA flares have occurred usually include spots of opposite polarity in close proximity (usually less than one degree heliographic). Magnetic measurements at the McMath-Hulbert Observatory, made by Teske, of the spot group with the PCA flare of 16 September 1963, provide an additional example of this type of spot in association with a proton ejection.

In general, proton flares have taken place in flare-rich regions with large, complex spots. However, only relatively small fractions of the regions with these characteristics have produced flares with subsequently observed protons in the neighbourhood of the Earth (Table 13).

Consideration of the age of the regions in conjunction with the above characteristics strengthens the evidence that age or maturity may be a necessary aspect of a region before major flares, even with strong type IV emission, yield high-energy protons detectable in the neighborhood of the Earth by methods currently in use. Figure 4 shows the age of the calcium plage regions (not the age of the associated spot) in which PCA flares have taken place; the distribution, by age, of the regions with flares emitting type IV radiation with distinction between PCA regions and non-PCA regions; and corresponding data for regions with the largest spots.* Similar studies have been made for other characteristics

* The data for the largest spots is based on the Mount Wilson yearly summaries of large spots of area $>1000$ millionths of the hemisphere, and is complete only through 1960 . 
TABle 13. Number of Regions WITH CERTAIN CHARACTERISTICS COMPARED to REGIONS WITH PROTON FLARES

\begin{tabular}{|c|c|c|c|}
\hline $\begin{array}{l}\text { Characteristics of regions } \\
\text { that appear to favor } \\
\text { occurrence of proton flares }\end{array}$ & $\begin{array}{c}\text { Total } \\
\text { number }\end{array}$ & $\begin{array}{l}\text { ith } \\
\text { tics } \\
\text { Number } \\
\text { with PCA } \\
\text { flares }\end{array}$ & $\begin{array}{l}\text { Total } \\
\text { number of } \\
\text { regions with } \\
\text { PCA flares } \\
\text { for years } \\
\text { indicated }\end{array}$ \\
\hline $\begin{array}{l}\text { "Flare-rich "; } 1957-1961 \\
\text { (25 most flare-rich in each year.) }\end{array}$ & 125 & 27 & 34 \\
\hline $\begin{array}{l}\text { Flares with type IV emission; } \\
1957-1961\end{array}$ & 70 & $26^{*}$ & 34 \\
\hline $\begin{array}{l}\text { Fifty largest spots; } 1957-1960 \\
\text { (Mount Wilson data) }\end{array}$ & 50 & 11 & 31 \\
\hline $\begin{array}{l}\text { Spots with area }>1000 \text { millionths of } \\
\text { hemisphere; } 1955-1960 \text { (Mount } \\
\text { Wilson data) } \\
\beta \gamma \text { spots; 1955-1960 (Mount }\end{array}$ & 75 & 11 & 34 \\
\hline $\begin{array}{l}\text { Wilson classification) } \\
\gamma \text { spots; } 1955-1960 \text { (Mount }\end{array}$ & 61 & 14 & 34 \\
\hline $\begin{array}{l}\text { Wilson classification) } \\
\beta \gamma \text { or } \gamma \text { spots; } 1955-1960 \text { (Mount }\end{array}$ & 32 & 9 & 34 \\
\hline $\begin{array}{l}\text { Wilson classification) } \\
\beta \gamma \text { or } \gamma \text { spots and spot area }>1000\end{array}$ & 93 & 23 & 34 \\
\hline millionths of hemisphere, $1955-1960$ & 32 & 12 & 34 \\
\hline
\end{tabular}

* It is possible that this number should be larger because PCA flares occurred in eight regions at times when dynamic spectra were not being obtained.

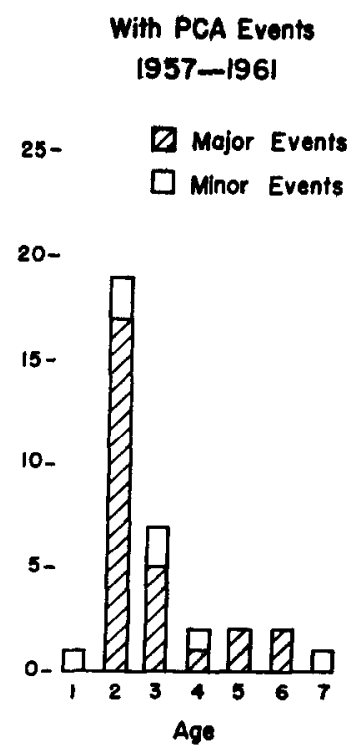

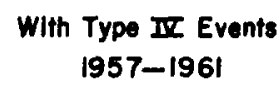

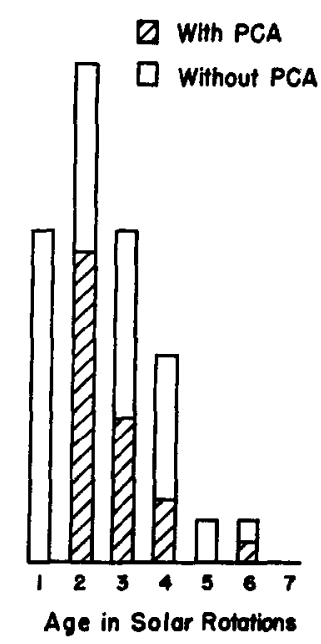

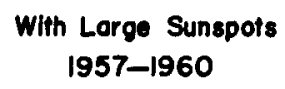

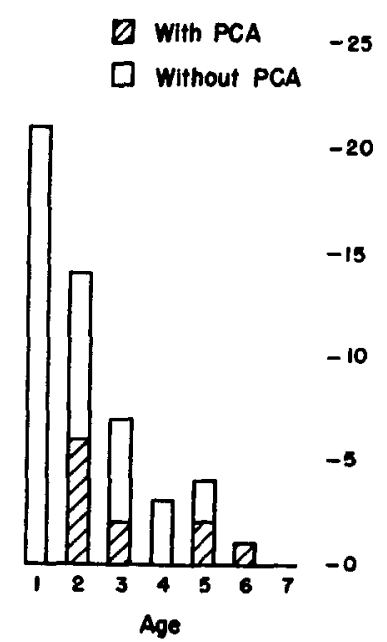

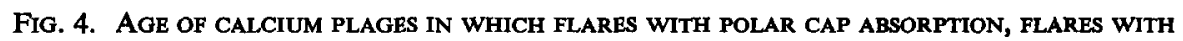
TYPE IV EMISSION AND THE LARGEST SPOTS, HAVE OCCURRED. 
of PCA flares and regions, and in each case, the introduction of age of region is of assistance in narrowing the distinction between proton-producing flares and relatively similar flares without associated PCA at the Earth.

The above data refer to the occurrence of proton-producing flares when the regions in question have been on the hemisphere of the Sun turned towards the Earth. Evidence is exceedingly limited for the occurrence of PCA with events in regions centered more than 10 or $20^{\circ}$ around the solar limb on the invisible hemisphere. Accordingly, the above comparisons between potential proton-flare-regions and observed proton events must eventually be modified by consideration of the probable occurrence of proton flares on the invisible hemisphere and the total genealogy and relationships of the known PCA-flare-regions.

If these studies are meaningful they suggest that solar protons arrive near the Earth only after an active center on the Sun has evolved to some critical point at which it is capable of producing special kinds of flares, or after the region has developed a bottle, stream or coronal feature that makes it easier for high-energy particles produced during flares to leave the Sun and reach the Earth. In the future, better understanding of the overall development and growth of plages and centers of activity may be of assistance in efforts to recognize the potential proton-producing regions and to distinguish between flares with and without associated proton events in the neighborhood of the Earth.

Acknowledgement-The authors are grateful to R. Jayanthan for his generous assistance in the preparation of data for this study. The preparation of this study has been assisted by support from Contract Nonr1224(19) of the Office of Naval Research.

\section{REFERENCES}

1. IGY Solar Activity Report Series Nos. 12, 15, 18, 21; IGY World Data Center A, HAO, Boulder, Colorado.

2. H. W. Dodson and E. R. Hedeman, J. Geophys. Res. 65, 123 (1960).

3. IGY Solar Activity Report Series No. 17, IGY World Data Center A, Boulder, Colorado.

4. L. Acton, J. Geophys. Res. 66, 3060 (1961).

5. M. A. Ellison, J. Atmos. Terr. Phys. 4, 226 (1953).

6. K. Davies, Proceedings of the International Conference on the Ionosphere, p. 76. Institute of Physics and the Physical Society, London (1962).

7. C. WARWICK and M. WOOD, Astrophys. J. 129, 801 (1959).

8. M. A. Ellison, Dunsink Obs. Publ. 1, 1 (1960).

9. H. W. Dodson, E. R. Hedeman and A. E. Covington, Astrophys. J. 119, 541 (1954).

10. M. Martres and M. PicK, Ann. Astrophys. 25, 293 (1962).

11. J. M. MALville and S. F. Simith, J. Geophys. Res. 68, 3181 (1963).

12. A. E. Covington and G. Harvey, Nature, Lond. 192, 152 (1961).

13. R. Grant Athay and Gait E. Moreton, Astrophys. J. 133, 935 (1961).

14. K. ANGLE, Paper presented at AAS meeting, Alaska (July, 1963).

15. R. W. Kreplin, T. A. Chubb and H. Friedman, J. Geophys. Res. 67, 2231 (1962).

16. L. W. Acton, T. A. Chube, R. W. Kreplin and J. F. Meekins, J. Geophys. Res. 68, 3335 (1963).

17. M. KundU, J. Geophys. Res. 66, 4308 (1961).

18. T. FORTIN, Astrophys. J. 138, 278 (1963).

19. H. W. Dodson, E. R. Hedeman and R. R. McMath, Astrophys. J. Suppl. 2, 241 (1956).

20. Th. SAemundsson, Mon. Not. Roy. Astr. Soc. 123, 299 (1962).

21. B. Bell, Smithson. Contr. Astrophys. 5, 239 (1963).

22. A. MAXWell, A. R. Thompson and G. Garmire, Planet. Space Sci. 1, 328 (1959).

23. J. A. Roberts, Aust. J. Phys. 12, 327 (1959).

24. K. SinNo and Y. HAKURA, Rep. Ionosph. Res. Japan 12, 285 (1958).

25. D. J. Mclean, Aust. J. Phys. 12, 404 (1959).

26. P. SimON, Ann. Astrophys. 23, 102 (1960).

27. L. D. DeFeiter, A. D. Fokker, H. P. T. Lohulzen and J. Roosen, Planet. Space Sci. 2, 223 (1960).

28. M. Pick-Gutmann, Ann. Astrophys. 24, 183 (1961).

29. E. R. MUSTEL and N. B. YeGOROVA, Researches of IGY, No. 1, 1 Dokl. Akad. Nauk SSSR. (1961).

30. H. Maeda, K. SakuraI, T. Ondoh and M. Yamamoto, Ann. Géophys. 18, 305 (1962).

31. C. S. WARWICK and M. W. HAURWITZ, J. Geophys. Res. 67, 1317 (1962). 
32. H. Dodson and E. R. Hedeman, J. Geophys. Res. 63, 77 (1958).

33. R. W. Jenkins and I. Paghis, Canad. J. Phys. 41, 1056 (1963).

34. B. Bell, Smithson. Contr. Astrophys. 5, 69 (1961).

35. H. Dodson and E. R. Hedeman. Astr. J. 65, 51 (1960).

36. J. G. Wolbach, Smithson. Contr. Astrophys. 8, 101 (1963).

37. H. Dodson, Proc. Nat. Acad. Sci. 47, 901 (1961).

38. M. J. MARTres and M. Pick, Ann. Astrophys. 25, 293 (1962).

39. George B. Hale, Astrophys. J. 73, 379 (1931).

40. H. Dodson, Astrophys. J. 110, 382 (1949); 115, 320 (1952); and R. McMATH, 115, 78 (1952).

41. M. A. Ellison, S. M. P. McKenna and J. H. ReID, Dunsink Obs. Publ. 1, 53 (1961).

42. H. Dodson, Trans. IAU 11b, 474 (1962).

43. J. Bartels, Ann. Géophys. 19, 1 (1963).

44. D. A. Bryant, T. L. Cline, U. D. Desai and F. B. McDonald, Goddard Space Flight Center Publication X-611-63-158, (July, 1963).

45. Y. Avignon and M. Pick-Gutmann C. R. Acad. Sci., Paris 249, 2276 (1959).

46. M. KUNDU and F. HADDOCK, Nature, Lond. 186, 610 (1960).

47. A. R. ThOMPSON and A. MAXwell, Nature, Lond. 185, 89 (1960).

48. G. ReID and H. LeINBACH, J. Geophys. Res. 64, 1801 (1959).

49. H. Dodson and E. R. Hedeman, Ark. Geofys. 3, 469 (1961).

50. T. Obayashi, J. Geophys. Res. 67, 1717 (1962).

51. Y. Avignon, M. J. Martres-Tropes and M. Pick-Gutmann, C.R. Acad. Sci., Paris 256, 2112 (1963). 